\title{
ANNOUNCEMENTS \\ Xian Laboratory of Loess Quaternary Geology
}

Xian. Shaanxi Province, People's Republic of China

The Xian Laboratory of Loess Quaternary Geology is a newly established research unit of Academia Sinica and a part of the Xian Branch of Academia Sinica. The institute is located in Xian, Shaanxi Province, which is famous geographically for its well-developed loess plateau. The Loess Plateau is the cradle of the ancient Chinese culture and also a center of agriculture and industry in northwest China. In this region is found a thick loess-paleosol sequence, deposition of which began 2.4 million years ago. It provides one of the best available indicators of Quaternary climatic changes in China and contains abundant early human remains (Homo erectus Lantieninsis).

The first director of the new institute is Professor Liu Tungsheng, vice president of INQUA and president of the China Association for Quaternary research. An Zhisheng is deputy director. The academic commission of the institute includes Quaternary geologists (Professor Liu Tungsheng and Dr. An Zhisheng), a pedologist (Professor Zhu Xianmo), a loess specialist (Professor Wang Yongyian), an engineering geologist (chief engineer Lin Zaiguan), and others. A group of young research fellows are involved in various aspects of Quaternary geology. They include Zhu Yizhi (Quaternary geology), Liu Rongmo (stable isotope geology), Zhou Mingfu (radiocarbon dating), Zhang Guangyu (geochemistry), and Gao Wanyi (cartography).

The main research projects of the institute include investigations on the characteristics and processes of Quaternary sediments and loess. By understanding the geological-biological records of the Quaternary, it is possible to reconstruct the history of Quaternary environmental changes in the Loess Plateau, to explore the impact of human activities on the past and future, and to suggest schemes for protection of nature and development of land resources.

The institute is ideally situated for field studies in a wide range of environments and on a variety of other topics as well. In addition to loess and paleosols, which are well exposed in the surrounding region, fluvial, glacial, and lacustrine sediments are available for investigation. Studies of various geomorphic processes, especially aspects of weathering, mass-wasting, and erosion, can also be pursued conveniently. The institute is dedicated to fostering interdisciplinary investigations that can provide important insights into Quaternary processes and environmental history.

Several laboratories involved in these research projects are now under construction: Radiocarbon laboratory, laboratory of stable isotopes, laboratory of thermoluminesence, laboratory of chemical analysis, laboratory of soil micromorphology, and laboratory of physical/mechanical testing of loess and Quaternary sediments. 
Persons wishing to contact the laboratory may write to:

Xian Laboratory of Loess and Quaternary Geology

Academia Sinica

P.O. Box 17

Xian, Shaanxi Province

People's Republic of China

\title{
Symposium on Remote Sensing in Anthropology and Archaeology
}

\author{
Washington, D.C., December 1985
}

A day-long symposium on Remote Sensing in Anthropology and Archaeology, co-chaired by Payson Sheets (University of Colorado) and Scott Madry (University of North Carolina, Chapel Hill), will be held on December 6th or 7th at the Washington Hilton during the 1985 Annual Meeting of the American Anthropological Association. Among topics to be addressed are ethical questions concerning the use of remote sensing in anthropology (especially third-world contexts), future technologies and directions of research, and the proposed commercialization of LANDSAT and the effects of other policy decisions on research. Participants in the symposium are many of the more active researchers in remote sensing, and an ample discussion period has been planned. Those who are already knowledgeable and those who would like to become knowledgeable about how remote sensing technology is being integrated into anthropological and archaeological research designs are cordially invited to attend.

For further information please contact:

\author{
Scott Madry \\ Department of Antropology \\ University of North Carolina \\ Chapel Hill, North Carolina 27514
}

\section{9th Biennial Meeting of the American Quaternary Association}

\author{
Champaign, Illinois, June 2-4, 1986
}

The American Quaternary Association will hold its 9th biennial meeting at the University of Illinois-Champaign from June 2 to 4, 1986. The theme for the conference will be Environments at Glacier Margins-Past and Present. Field trips to nearby type sections and archaeological sites will be held both before and after the meetings. For information, please contact:

Wayne M. Wendland

AMQUA Local Arrangements Committee

Illinois State Water Survey

2204 Griffith Drive

Champaign, Illinois 61820

Telephone: (217) 333-0729 